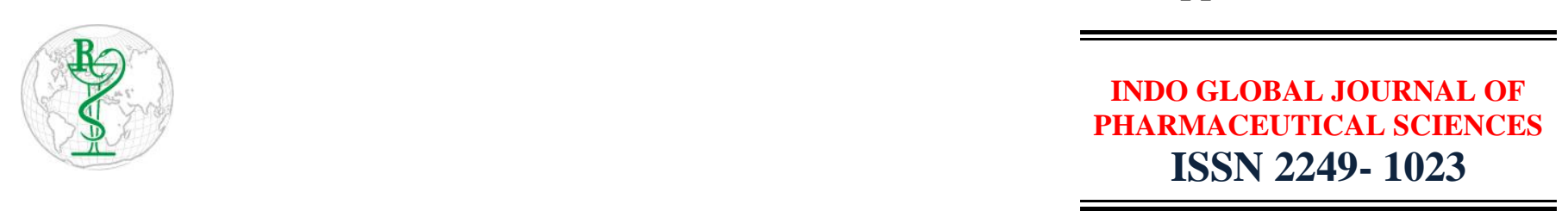

\title{
Nanotechnology: A Novel Approach for the Prevention of Anaemia
}

Address for Correspondence: Kuldeep Singh; kuldeeppharma90@ gmail.com

\begin{abstract}
Received:
01.03.2019

Accepted:

25.03.2019

Keywords

Nanoformulation

$\mathrm{s} ;$ Blood

Disorders;

Nanomaterials.
\end{abstract}

\author{
Kuldeep Singh ${ }^{* 1,2}$, Dimple Chopra ${ }^{2}$ \\ ${ }^{1}$ Sri Sai College of Pharmacy, Manawala, Amritsar-143115, Punjab, India \\ ${ }^{2}$ Department of Pharmaceutical Sciences and Drug Research, Punjabi University, Patiala- 147002
}

ABSTRACT: Anaemia is the most common nutritional disorder that afflicts a staggering number of 2 billion people, i.e. over $30 \%$ of world population around the globe. Gastrointestinal adverse effects of soluble iron supplements due to redox cycling also constitute a major barrier to treatment of iron deficiency anaemia. Recently; there has been a surge in the development of nanotechnology-based delivery systems for the targeted delivery of many drugs or to enhance the bioavailability of various drugs in the body. The important technological advantages of nanoformulations as drug carriers are high stability, feasibility of incorporation of both hydrophilic and hydrophobic substances, and feasibility of variable routes of administration, including oral application and inhalation. The primary applications of nanomaterials in drug delivery are to make the drug safer and more biocompatible, to reduce its toxicity without compromising with its therapeutic potential, for specific and targeted drug delivery and to increase its bioavailability and absorption in the body. The development of these nano-disperse, destructured iron hydroxides nano-formulations that mimic how the gut digests normal dietary ferric iron (i.e. non-heme iron). These structures are bioavailable in vivo without any requirement for prior luminal or mucosal reduction. Various nano carriers like nano emulsion, nano spheres, nano liposomes etc. has paid much attention to deliver the drug in therapeutic concentration for longer period of time to enhance the bioavailability and absorption of the drug in the gastrointestinal tract. This review article highlights the research trends and challenges of nanotechnology based drugs to combat iron deficiency anaemia. (C) 2019 iGlobal Research and Publishing Foundation. All rights reserved.

Cite this article as: Singh, K.; Chopra, D. Nanotechnology: A Novel Approach for the Prevention of Anaemia. Indo Global J. Pharm. Sci., 2019; 9(2Suppl.): 152. DOI: http://doi.org/10.35652/IGJPS.2019.92S50

Indo Global Journal of Pharmaceutical Sciences( ISSN 2249 1023; CODEN- IGJPAI; NLM ID: 101610675) indexed and abstracted in CrossRef (DOI Enabling), UGC CARE Journal List, EMBASE(Elsevier), National Library of Medicine (NLM) Catalog, ResearchGate, Publons, CAS (ACS), Index Copernicus, Google Scholar and many more. For further details, visit http://iglobaljournal.com

This is a special issue as an outcome of 'RAPSCON-2019' sponsored by APTI and organized by Sri Sai College of Pharmacy, Manawala, Amritsar, Punjab, India. Relaxation offered in journal format. 